\title{
Nuestro plan de estudios también necesita primeros auxilios
}

\author{
M. Torres-Amengual
}

Una de las ilusiones más acertadas del estudiante de medicina de 3 er $^{\text {er }}$ curso es entrar en contacto con su primer paciente. Este acercamiento, así como los siguientes, se producirá en un centro sanitario y bajo la atenta mirada de profesores y residentes, que se encargarán de supervisarlo a lo largo de los próximos dos meses. Durante estas prácticas el alumno aprenderá a realizar una anamnesis completa y algunas nociones de exploración física. Pero, ¿es esto suficiente? ¿Es acaso el alumno, justo en el meridiano de su carrera o incluso al final de la misma, tras seis años de formación, capaz de hacer frente a cualquier incidente, por leve que sea, que pueda presentarse en la vida diaria? La experiencia demuestra que el alumno no es tan sólo incapaz de reaccionar ante emergencias tales como quemaduras, traumatismos, atragantamientos, etc. cuando éstos tienen lugar fuera del recinto hospitalario (en la calle, en el hogar, etc.), sino que, además, tampoco posee el aplomo, la habilidad y la destreza básicos para tratar al paciente/víctima y así desenvolverse con éxito en semejantes situaciones.

Si analizamos el Plan de Estudios aprobado en 2001 [1], se observa que no se dedica un sólo crédito a primeros auxilios en toda la carrera. Por otro lado, la relación médico-paciente no empieza a tener lugar hasta el final del $3 .^{\text {er }}$ curso, de modo que se desaprovecha un tiempo precioso en el que el alumno bien podría haber aprendido a desarrollar ese valioso nexo y a comprender la empatía que éste supone, para poder dedicarse ya en tercero a adquirir más conocimientos médicos (p. ej., primeros auxilios). Es por ello que muchos estudiantes tienen que recurrir a cursillos y otras formaciones complementarias que le permitan rellenar ese inmenso vacío. Es el caso del curso de socorrismo básico ofrecido por la Cruz Roja [2], que dura 40 horas y para el que no se necesitan conocimientos previos, pues el manual que ofrecen es de lo más completo e ilustrativo. Cualquier ciudadano de a pie bienintencionado puede acceder a estas clases $y$, tras las mismas, convertirse en voluntario para trabajar en ambulancias. Sé de más de un médico/ estudiante de medicina que ha recurrido a estos voluntarios porque no sabían cómo hacer frente a la situación; estaban literalmente paralizados. Conclusión: un estudiante de empresariales que haya tenido que realizar éste $u$ otro curso de semejantes características (p. ej., técnico en emergencias sanitarias [3], de tan sólo 50 horas) está sobradamente más preparado que un estudiante de $4 .^{\circ}$ curso de medicina. Raya lo inverosímil.

Esta situación no se da en todos los países. Facultades como las de Colombia [4] o Suecia [5], entre otras, ofrecen durante el primer semestre una asignatura troncal de primeros auxilios, pues quizá hayan comprendido que a pesar de la falta de conocimientos en anatomía o fisiología, los conceptos que aquí desean transmitirse son de vital importancia para convertirse en un buen facultativo, capaz de adaptarse y reaccionar desde el principio a cualquier situación adversa. Otras facultades como Oxford [6] (Reino Unido), British Columbia [7] (Canadá), Chinese University of Hong Kong [8] (China), etc. son partidarias de enviar a sus estudiantes junto al lecho de los pacientes desde el primer día. Colaboran en hospitales, consultas externas y visitan en el propio domicilio del enfermo. Todo un
Facultad de Medicina. Universitat de Barcelona. Barcelona, España.

E-mail tricuspide22@hotmail.com 
ejemplo de cómo adquirir habilidades y destreza necesarias en la empatía, el trato y la supervisión de los pacientes.

Algo falla cuando, frente a un accidente de tráfico, lo mejor (y de hecho lo único) que puede hacer un estudiante de medicina es sentarse, describir a la perfección los cambios fisiopatológicos que se están produciendo en la víctima y observar cómo ésta fallece, mientras reza para que llegue una ambulancia con un estudiante de bellas artes en su interior que sepa hacer un torniquete en condiciones.

Al final va a resultar que nuestro Plan de Estudios también necesita primeros auxilios.

\section{Bibliografía}

1. UB-Facultad de Medicina. Licenciatura en Medicina: itinerario curricular. URL: http://www.ub.es/medicina/ medicina/itinerari/troncalsB.htm. [02.04.2008].

2. Cleaver B, Crawford R, Armstrong VJ, López Angón JL, coords. Manual de primeros auxilios. Avalado por Cruz Roja. Madrid: Pearson Educación; 2007.
3. Ruiz-Lorenzo FJ, Sánchez-Higuera M. Manual del técnico en emergencias sanitarias. 1 ed. Madrid: Aula Médica; 2000

4. Facultad de Medicina, Universidad de Antioquia, Medellín, Colombia. Pregrado de Medicina: plan de estudios. URL: http://medicina.udea.edu.co/programas/pregrado/ programas20071/Nivel1/PA20071.pdf. [06.04.2008].

5. Lund University Faculty of Medicine, Lund, Sweden. The Undergraduate Medical Program Lund University ECTS Catalogue: detailed information-semester 1. URL: http:// www.med.lu.se/english/education/undergraduate_studies/undergraduate_medical_education/ects_catalogue. [03.04.2008].

6. University of Oxford, Oxford, United Kingdom. Medical Sciences Office; 2006-2007 Study Medicine, courses overview. URL: http://www.medsci.ox.ac.uk/study/medicine/courses/overview. [02.05.2008].

7. UBC-Faculty of Medicine. The University British Columbia, Vancouver, Canada. Education, MD undergraduate program, schedule and courses: year 1 . URL: http://www.med.ubc.ca/education/md_ugrad/Schedule_Courses/Year_1.htm. [03.04.2008].

8. The Chinese University of Hong Kong, Faculty of Medicine, Hong Kong. Teaching Program, Medicine Curriculum. URL: http://www.med.cuhk.edu.hk/v7/s30_05. htm. [01.05.2008]. 